\title{
COPIM
}

\section{COPIM Newsflash! \#2 Project Update June 2020}

Lucy Barnes, Dan Rudmann, Tobias Steiner

Published on: Jun 22, 2020

DOI: $10.21428 / 785 a 6451 . c d 14 e b 38$

License: Creative Commons Attribution 4.0 International License (CC-BY 4.0). 
In May 2020, COPIM reached its first six-month mark, and a lot has happened in those few months!

We have been expanding our work to include many more stakeholders, with the Work Packages heavily invested in collecting input from different people and organisations through workshops, as well as doing research on a variety of reports. Since our last Newsflash, four more workshops have been organized - more details on these in the updates on work package activity below!

\section{WP1: Outreach \& Admin}

Much of our work in WP1 has been around establishing internal project communication, management processes and routines across all of our work packages. We have expanded our project presentation here on PubPub with workshop notes and talks now available, and we now also have our own email domain set up and running. You can reach us via the central contact address info@copim.ac.uk.

We now also have our COPIM Advisory_Board established, and updated the webpage to include more information about this amazing group and their background and expertise.

Further Outreach activities included participating in internal and external webinars, conferences and workshops, as well as the implementation of new community events with the amazing work done by our own Dan Rudmann together with the team at Coko in organizing the open Publishing Fest! Throughout the two week fest, COPIM advanced our community development efforts by hosting panel discussions on open infrastructure and the development alliances between open access presses and institutional libraries. COPIM members Lucy Barnes, Martin Eve, Vincent van Gerven Oei, and Sam Moore created sessions that were part of this wonderful celebration of all things Open Publishing! (In case we've now got you wanting to know more, check out the Open Publishing Fest $\underline{\text { Archives.) }}$

\section{WP2: Revenue Infrastructures and Management Platform}

Along with Elli Gerakopoulou, WP2 has seen further influx of expertise through our newest member Agata Morka, who has joined COPIM through our partner Open Book Publishers in her role as European Coordinator of Open Access Book Publishing, coordinating efforts between OPERAS-P and COPIM. Elli is continuing her work on the landscape study of consortial funding models, while Agata is conducting interviews 
with a broad range of stakeholders on a pan-European scale - research that will also inform Elli's landscape study.

Following on from our first publisher workshop that took place in March, a US-based workshop supported by the University of Michigan / Michigan University_Press and Lyrasis was held on May 13, focusing on libraries and publishers and in close collaboration with WPs 3 and 5. While this was originally planned to be held in Michigan, the workshop was reformatted as an online event due to the COVID-19 pandemic.

Further evolving this particular format, three more workshops have now been planned. An online workshop focusing on the UK landscape was held on June 16, involving leading members of the UK scholarly library community. And two more US-based workshops will include stakeholders from the United States' West and East coasts, so as to accommodate as broad a spectrum of US participants as possible.

\section{WP3: Knowledge Exchange and Piloting Alternative Business Models}

Izabella Penier has been continuing her work on the research/landscape report on existing publisher business models.

WP3 also participated in the Libraries and Publishers workshop (as discussed above) with publishers and infrastructure providers. Next to that, Martin Eve participated in a UKSG seminar on the topic of "Seeking_Sustainability: Publishing_Models for an Open Access Age"

Also, we're very excited to welcome our newest member Tom Grady to COPIM, who has now started in the position of a Scholarly Publishing_Outreach Officer. Bringing his long-standing experience in working with OA publisher White Rose University_Press to the project, Tom will support the work package by working closely with academic publishers to convert their business models to Open Access.

\section{WP4: Community Governance}

Sam Moore and Janneke Adema organized a workshop that took place on May 1, hosted by UCSB Library, on the topic of Community Governance for Open Monograph Publishing Infrastructures. Similar to the other workshops and in reaction to global events, this workshop has also been facilitated online.

Sam and Janneke have published three blogposts reflecting on their ongoing research: 
1. "Community Governance Explored", which was written in preparation for the workshop and as a foundation to inform the research the WP is undertaking,

2. as well as parts $\underline{\text { One }}$ and Two of their Community Governance Workshop Recap, which revisits the very fruitful conversations and underlying themes that were discussed during the workshop.

In addition, Sam and Janneke have also set up a Working Group on the Humanities Commons platform which will advise the COPIM project on all matters related to (community) governance and the long-term direction and management of consortial library funding programs. Please contact Sam and Janneke at governance@copim.ac.uk if you'd like to be added to the group.

\section{WP5: Building an Open Dissemination System}

Work continues on the scoping report for this WP, which should be completed within the next month or two. We have also published a report on March's workshop and what we learned.

Thoth, our metadata management system currently under development, is almost ready to begin its pilot with COPIM partners Open Book Publishers and punctum books.

The first draft of our scoping report for this work package is very nearly complete, and will be made publicly available in the coming weeks. Amongst other things, this report identifies many related initiatives that we will aim to make direct contact with in the coming months and as the project develops.

We are also in regular contact with OPERAS, where there are commonalities between WP5 and the Triple project. The work Jisc is currently doing on OA monographs also overlaps with COPIM and OPERAS - we are working to keep the communication channels open between the three organisations!

\section{WP6: Experimental Publishing, Re-use, and Impact}

All members of WP6 are now working towards identifying tools and platforms to use for our first two pilot cases, with a second experimental publishing pilot case now being developed in close collaboration with our partner Mattering Press.

Janneke is working on the first part of the scoping report, consisting of a mapping of Experimental Books, which is now nearing its first full draft stage. In addition, Sam is developing a literature review on Reuse and Collaborative Authorship. 
Planning for a workshop on 1 July is ongoing.

\section{WP7: Archiving and Digital Preservation}

The work package officially started on May 1, and recruitment for WP7 has progressed well. One of the two open research positions is now filled, and we are delighted that the excellent candidate will start in late Summer 2020 to take on the scoping element of the project. The WP is initially looking at the risks and challenges associated with preservation and has started identifying the main themes in these areas.

That's all folks! We will add reports on our upcoming workshops to the PubPub when they have been completed. Keep an eye out for these, and for more on our scoping reports!

Header image: adapted from British Library, $\underline{\text { CCO }}$ via Europeana 